Pacific Journal of Mathematics

ON THE CONSTRUCTION OF CERTAIN BOUNDED 


\title{
ON THE CONSTRUCTION OF CERTAIN BOUNDED CONTINUOUS FUNCTIONS
}

\author{
J.-P. KAHANE
}

We give an elementary method for constructing continuous functions fulfilling the hypothesis of Theorem 1 of the preceding paper. Such functions thus constitute counterexamples to the proposition and theorem discussed therein.

THEOREM. Let $\varphi(x)$ be continuously differentiable on $[0, \infty)$, and suppose

(i) $\varphi(0)=0$

(ii) $\varphi^{\prime}(x)$ is nonnegative, and strictly increasing to $\infty$ on $[0, \infty)$

Put

(iii) $\varphi^{\prime}(x) / \varphi(x) \rightarrow \infty, x \rightarrow \infty$.

$$
\begin{array}{ll}
f(x)=\sum_{1}^{\infty} 2^{-m} \exp \left(\frac{2 \pi i}{2^{m}} x\right), & x<0 \\
f(x)=e^{i \varphi(x)}, & x \geqq 0 .
\end{array}
$$

Then the bounded continuous function $f(x)$ has properties 1, 2, and 3 of Theorem 1 in the previous paper.

Proof. That $0 \in s p f$ follows from (1) as in $\S 2$ of the previous paper.

To establish property 3 , let us show that

$$
\frac{1}{T} \int_{0}^{T} f(x+a) d x \rightarrow 0
$$

uniformly in $a$ as $T \rightarrow \infty$. If $I$ is any interval of length $T$, denote by $A$ the part of $I$ lying to the left of 0 , and by $B$ that part lying to the right. We have, by (1),

$$
\frac{1}{T} \int_{A} f(x) d x=\frac{|A|}{T}\left\{\frac{1}{|A|} \int_{A} \sum_{1}^{\infty} 2^{-m} \exp \left(\frac{2 \pi i}{2^{m}} x\right) d x\right\} .
$$

The quantity in brackets is always in absolute value $\leqq 1$, and tends to zero independently of the position of $A$ as $|A| \rightarrow \infty$ (this fact belongs to the rudiments of the theory of almost periodic functions, and can here be verified by direct calculation). Since $|A| \leqq T$, we have

(3) $\frac{1}{T} \int_{A} f(x) d x \rightarrow 0$ independently of the position of $I$ as $T \rightarrow \infty$.

\footnotetext{
Received December 22, 1964.
} 
The integral $\int_{B} f(x) d x$ is bounded for all intervals $B$ of the form $[0, b]$. Indeed, if $b>1$,

$$
\int_{0}^{b} f(x) d x=\int_{0}^{1} f(x) d x+\int_{1}^{b} f(x) d x .
$$

Since $\varphi^{\prime}(x) \geqq 0$ we can, by (2), make the substitution $\varphi(x)=\xi$ in the second integral on the right, getting for it the value

$$
\int_{1}^{b} e^{i \varphi(x)} d x=\int_{\varphi(1)}^{\varphi(b)} e^{i \xi} \frac{d \xi}{\varphi^{\prime}(x)}
$$

In view of (ii), this last is in absolute value $\leqq 4 / \varphi^{\prime}(1)$ by the second mean value theorem. It follows that $\int_{B} f(x) d x$ is bounded for all intervals $B$ lying to the right of the origin, whence

(4) $\frac{1}{T} \int_{B} f(x) d x \rightarrow 0$ independently of the position of $I$ as $T \rightarrow \infty$.

From (3) and (4) we see that $1 / T \int_{I} f(x) d x$ is small in absolute value for all intervals $I$ of length $T$, if only $T$ is sufficiently large, which is property 3 .

It remains to verify property 2 . We show that if $0<X_{1}<\cdots<X_{M}$ and the $A_{k}$ are complex numbers

$$
\sup _{x>0}\left|\sum_{k=1}^{M} A_{k} e^{i \varphi\left(x+x_{k}\right)}\right|=\sum_{1}^{M}\left|A_{k}\right| \text {. }
$$

So as not to lose the reader in details, we do this for the case $M=2$; it will be clear how to extend the reasoning to any value of $M$.

Let $\varepsilon$ be given, $0<\varepsilon<\pi / 2$, and, choosing a positive determination of the argument, put, for $k=1,2,3, \cdots$

$$
\begin{aligned}
& a_{k}=\varphi^{-1}\left(2 \pi k+\arg \frac{1}{A_{1}}-\varepsilon\right)-X_{1} \\
& b_{k}=\varphi^{-1}\left(2 \pi k+\arg \frac{1}{A_{1}}+\varepsilon\right)-X_{1} .
\end{aligned}
$$

Clearly $a_{k}<b_{k}<a_{k+1}, a_{k} \rightarrow \infty$ as $k \rightarrow \infty$, and by (ii),

$$
b_{k}-a_{k} \rightarrow 0, k \rightarrow \infty \text {. }
$$

Also,

$$
\mathscr{R}\left(A_{1} e^{i \varphi\left(x+X_{1}\right)}\right) \geqq\left(1-\varepsilon^{2}\right)\left|A_{1}\right| \text { for } a_{k} \leqq x \leqq b_{k} .
$$

I claim that $\varphi\left(b_{k}+X_{2}\right)-\varphi\left(a_{k}+X_{2}\right) \rightarrow \infty$ as $k \rightarrow \infty$. If $c>0$, by (ii): 


$$
\frac{\varphi^{\prime}(x+c)}{\varphi^{\prime}(x)} \geqq c \frac{\varphi^{\prime}(x+c)}{\varphi(x+c)-\varphi(x)} \geqq c \frac{\varphi^{\prime}(x+c)}{\varphi(x+c)},
$$

whence

$$
\frac{\varphi^{\prime}(x+c)}{\varphi^{\prime}(x)} \rightarrow \infty, x \rightarrow \infty
$$

in view of (iii). Since $X_{2}>X_{1}$, there is, by (8), a $c>0$ such that, for all sufficiently large $k, c+b_{k}+X_{1} \leqq a_{k}+X_{2}$. We thus have, from (6), (7), (ii), and (10):

$$
\begin{aligned}
\varphi\left(b_{k}+X_{2}\right)-\varphi\left(a_{k}+X_{2}\right) & =2 \varepsilon \frac{\varphi\left(b_{k}+X_{2}\right)-\varphi\left(a_{k}+X_{2}\right)}{\varphi\left(b_{k}+X_{1}\right)-\varphi\left(a_{k}+X_{1}\right)} \\
& \geqq 2 \varepsilon \frac{\varphi^{\prime}\left(b_{k}+X_{1}+c\right)}{\varphi^{\prime}\left(b_{k}+X_{1}\right)} \rightarrow \infty
\end{aligned}
$$

as $k \rightarrow \infty$, since $b_{k} \rightarrow \infty, k \rightarrow \infty$. This is the desired result which implies, in particular, the existence, for all sufficiently large $k$, of an $x_{k} \in\left[a_{k}, b_{k}\right]$ such that

$$
\varphi\left(x_{k}+X_{2}\right) \equiv \arg \frac{1}{A_{2}}(\bmod 2 \pi) .
$$

For such $x_{k}$ we have $A_{2} e^{i \varphi\left(x_{k}+X_{2}\right)}=\left|A_{2}\right|$ which, together with (9), yields (5) for the case $M=2$, since $\varepsilon>0$ is arbitrary.

Remark. Suppose $\varphi(x)$ is even, and fulfills condition (i), (ii), and (iii) of the theorem. Besides this, let it be twice continuously differentiable, and be such that $\varphi^{\prime \prime}(x) \geqq C>0$ (example: $\varphi(x)=e^{x^{2}}$ ). Then, if $f(x)=e^{i \varphi(x)}, e^{i \lambda x}$ is not, for any $\lambda \in s p f$, in the weak closure of any bounded subset of $V_{f}$ (notation as in the preceding paper). (This observation is due to P. Koosis.)

Indeed, the function $f(x)$ clearly has property 2 , according to the above work. A glance at the proof of Theorem 1 in the preceding paper now shows that the desired result will certainly follow if we establish, for all real $\lambda$, that

$$
\frac{1}{T} \int_{0}^{T} f(x+X) e^{-i \lambda x} d x \rightarrow 0 \text { uniformly in } X \text { as } T \rightarrow \infty \text {. But by a }
$$

lemma of Van der Corput ([1], vol I, p. 197),

$$
\left|\int_{0}^{T} e^{2[\varphi(x+X)-\lambda x]} d x\right| \leqq 12 \cdot\left\{\inf _{0 \leqq x \leqq T} \varphi^{\prime \prime}(x+X)\right\}^{-1 / 2} \leqq 12 C^{-1 / 2}
$$

for all $T$, which implies the desired statement. 


\section{REFERENCES}

1. P. Koosis, On the spectral analysis of bounded functions, Pacific J. Math. 15 (1965),

2. A. Zygmund, Trigonometric Series, Second Edition, Cambridge, 1959.

Faculty of Sciences, ORSAy, University of Paris 


\section{PACIFIC JOURNAL OF MATHEMATICS}

EDITORS

H. SAMELSON

Stanford University

Stanford, California

R. M. BLUMENTHAL

University of Washington

Seattle, Washington 98105
*J. DUGUNDJI

University of Southern California

Los Angeles, California 90007

RICHARD ARENS

University of California

Los Angeles, California 90024

\section{ASSOCIATE EDITORS}

E. F. BECKENBACH

B. H. NeumanN

F. WOLF

K. YosidA

\section{SUPPORTING INSTITUTIONS}

UNIVERSITY OF BRITISH COLUMBIA

CALIFORNIA INSTITUTE OF TECHNOLOGY

UNIVERSITY OF CALIFORNIA

MONTANA STATE UNIVERSITY

UNIVERSITY OF NEVADA

NEW MEXICO STATE UNIVERSITY

OREGON STATE UNIVERSITY

UNIVERSITY OF OREGON

OSAKA UNIVERSITY

UNIVERSITY OF SOUTHERN CALIFORNIA
STANFORD UNIVERSITY

UNIVERSITY OF TOKYO

UNIVERSITY OF UTAH

WASHINGTON STATE UNIVERSITY

UNIVERSITY OF WASHINGTON

AMERICAN MATHEMATICAL SOCIETY CHEVRON RESEARCH CORPORATION

TRW SYSTEMS

NAVAL ORDNANCE TEST STATION 


\section{Pacific Journal of Mathematics}

\section{Vol. 16, No. $1 \quad$ November, 1966}

Larry Armijo, Minimization of functions having Lipschitz continuous first

partial derivatives ............................... 1

Edward Martin Bolger and William Leonard Harkness, Some

characterizations of exponential-type distributions.............. 5

James Russell Brown, Approximation theorems for Markov operators ...... 13

Doyle Otis Cutler, Quasi-isomorphism for infinite Abelian p-groups ...... 25

Charles M. Glennie, Some identities valid in special Jordan algebras but not valid in all Jordan algebras .......................... 47

Thomas William Hungerford, A description of $\operatorname{Mult}_{i}\left(A^{1}, \cdots, A^{n}\right)$ by

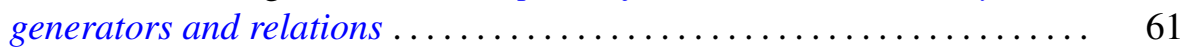

James Henry Jordan, The distribution of cubic and quintic non-residues ....

Junius Colby Kegley, Convexity with respect to Euler-Lagrange differential operators................................... 87

Tilla Weinstein, On the determination of conformal imbedding ......... 113

Paul Jacob Koosis, On the spectral analysis of bounded functions ........ 121

Jean-Pierre Kahane, On the construction of certain bounded continuous functions ................................... 129

V. V. Menon, A theorem on partitions of mass-distribution ........... 133

Ronald C. Mullin, The enumeration of Hamiltonian polygons in triangular

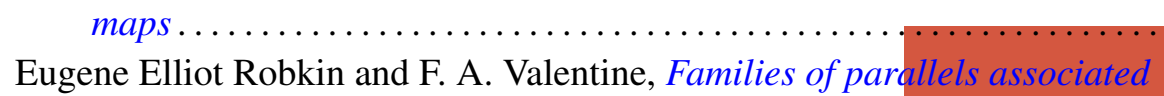

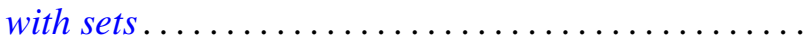

Melvin Rosenfeld, Commutative F-algebras

A. Seidenberg, Derivations and integral closure

S. Verblunsky, On the stability of the set of exponents of a Cauchy

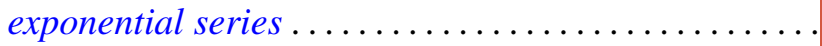

Herbert Walum, Some averages of character sums 